\title{
Quality Changes of Pear during Shelf-Life
}

\author{
T. ZSOM ${ }^{1}, *$, V. ZsOM-MUHA ${ }^{2}$, D. L. DÉNES ${ }^{2}$, L. BARANYAI ${ }^{2}$, J. FELFÖLDI ${ }^{2}$
}

\begin{abstract}
The aims of our research work were the investigation of postharvest changes of pear samples (Pyrus communis cv. Bosc kobak) during combined cold storage and shelf-life (storage at room temperature), the determination of quality changes by mainly non-destructive methods, the modeling of the changes of the non-destructive parameters (acoustic, impact stiffness coefficient, chlorophyll fluorescence parameters $\left[F_{v} / F_{m}, F_{m} / F_{0}\right]$ ), and multivariate statistical analysis of the measured and predicted data based on the data of the non-destructive texture analysis (acoustic and impact methods), chlorophyll fluorescence analysis and laser scattering measurement. Storage Time Equivalent Value $(S T E V)$ was calculated and introduced based on mass-loss analysis. The changes of the non-destructive parameters were analyzed vs. this virtual storage time (STEV). The changes of acoustic, impact stiffness coefficient and chlorophyll fluorescence parameters can be predicted by exponential function. The predicted time constants of the parameters were 21.0, 45.8, 47.1, 83.4, acoustic, impact stiffness coefficient, $F_{m} / F_{0}, F_{v} / F_{m}$, respectively. The lower the time constant, the quicker is the change of the given parameter during storage, the higher is its sensitivity. By this point of view, the percentage mass loss related sensitivity to the characterization of textural changes, the predicted acoustic stiffness coefficient was found to be more sensitive than the impact stiffness coefficient. The $F_{m} / F_{0}$ value characterized more sensibly the changes of the chlorophyll fluorescence than in the literature commonly used $F_{v} / F_{m}$. The non-contact laser scattering method based significant PLS models were constructed to predict the quality related pear characteristics (mechanical properties, chlorophyll fluorescence parameters).
\end{abstract}

Keywords: acoustic, impact, stiffness, chlorophyll fluorescence, laser scattering

\section{Introduction}

Fruits and vegetables are extremely sensitive and perishable products. They are still living after harvest and physiological processes such as respiration, transpiration, heat production, etc. continue to function. These processes significantly affect product quality and shelf-life. In case of fruits and vegetables the proper quality is the main criteria of marketability. For this reason, the determination of objective quality characteristics is highly

* Corresponding author. Phone: +36 1 305-7662, E-mail: Zsom.Tamas@etk.szie.hu

1Department of Postharvest Science and Sensory Evaluation, Faculty of Food Science, Szent István University, H-1118 Ménesi út 43-45, Budapest, Hungary

2Department of Physics and Control, Faculty of Food Science, Szent István University, H-1118 Somlói út 14-16, Budapest, Hungar 
needed. Knowledge of the objective parameters provides us the possibility for quality prediction. In order to achieve this goal, novel non-destructive methods are to be used. Novel non-destructive methods, such as chlorophyll fluorescence analysis, the acoustic impulse response technique, the impact method and backscattering imaging with laser light technique offer the possibility to non-destructively characterize fruit responses (e.g. physiological status, stage of maturation) to different external stressors, to quantify or predict produce quality and their postharvest changes.

Among novel non-invasive measuring methods, the chlorophyll fluorescence analysis has become a valuable and very informative tool for plant physiology and postharvest research in the last decades. The amount of chlorophyll fluorescence - emitted by the photosynthetically active chlorophyll molecules - is in close connection with the integrity (e.g. severity of an injury), the activity or inhibition and efficiency of the photosystem II (PSII) in green plants (e.g. fruits and vegetables) (von Willert et al., 1995). A part of the solar energy absorbed by the chlorophylls can be utilized to drive photosynthesis; excess energy can be emitted as heat or reemitted as invisible chlorophyll fluorescence (in wavelength range about $680-720 \mathrm{~nm}$ ) with the amount of about 1-3\% of the total absorbed amount of light energy (Herppich, 2001; Krause and Weis, 1991; Maxwell and Johnson, 2000; von Willert et al., 1995).

According to the Kautsky effect (Krause and Weis, 1991), in a dark adapted chlorophyll containing tissue the chlorophyll fluorescence is minimal $\left(F_{0}\right)$. After transferring into the light an increase in the yield of chlorophyll fluorescence occurs over a time period of about $1 \mathrm{~s}$ reaching the maximum fluorescence $\left(F_{m}\right)$.

The variable fluorescence is calculated as $F_{v}=F_{m}-F_{0}$. The $F_{v} / F_{m}$ value (ratio of variable to maximal fluorescence), the potential maximal photochemical efficiency of PSII, has been classically established and frequently used as a sensitive indicator (maximum about 0.83-0.85) of inhibition, but also damage to photosystem II and, bearing in mind the close interconnection of light harvest and light use, of the entire photosynthetic apparatus. It also refers to the green tissue's photosynthetic activity, stability and to the photosynthetically active chlorophyll content indirectly (Maxwell and Johnson, 2000; van Kooten and Snel, 1990). For decades in the postharvest scientific research, the changes in $F_{0}$ and $F_{m}$ and the $F_{v} / F_{m}$ fluorescence values have been frequently analyzed. As an effect of physiological alterations (e.g. maturation, aging, chilling injury) caused by inner and outer factors the decrease of $F_{v} / F_{m}$ value can be reliably detected (Kosson 2003; Purvis, 2002; Bron et al., 2004; Yang et al., 2011; Zsom et al., 2010) by the use of the chlorophyll fluorometers. 
In the literature, analysis of the $F_{0}, F_{m}$ and the $F_{v} / F_{m}$ fluorescence values is typical, however, Bron et al. (2004) reported to have found the $F_{m} / F_{0}$ value for a reliable indicator too for the classification of papaya fruits into maturity stages. On the other hand, Nedbal et al. (2000) found the $F_{0} / F_{v}$ value as a reliable chlorophyll fluorescence indicator for the significant detection of intact and mould infected lemon surfaces.

Chlorophyll fluorescence analysis has been used for a wide range of purposes. It can be used to monitor physiological processes (e.g. maturation, ageing [Carrara et al., 2001; Bron et al., 2004]) and for the prediction and/or determination of the effects of cell or tissue damage caused by many stressors (e.g. microbial infection, low $\mathrm{O}_{2}$ and/or high $\mathrm{CO}_{2}$ concentration caused anaerobic stress [DeEll and Toivonen, 2000; Hitka, 2011; Mattheis and Rudell, 2011; Nedbal et al., 2000; Prange et al., 2002; Wright et al., 2010]). Furthermore, it is really useful for the determination and evaluation of the effects of temperature treatments (e.g. heat treatment [Funamoto et al., 2002; Woolf and Laing, 1996]; chilling injury [Fan et al., 2011; Kosson, 2003; Purvis, 2002; Tijskens et al., 1994; Yang et al., 2011]). The great advantage of the use of chlorophyll fluorescence measurement is that the damage or the change caused by natural processes or stress factors can be detected well before the characteristic visible and/or other way detectable symptoms appear affecting the vitality and quality of the product (DeEll et al., 1996; Saquet and Streif, 2002; van Kooten and Snel, 1990).

Novel resolved method was developed based on hyperspectral imaging in order to measure the optical properties of liquid foods (e.g. juice and milk) and they can be used for the monitoring of horticultural crops (Qin and Lu, 2007; 2008). A linear dependence was established between milk fat concentration and the scattering parameter. This measuring method is fast and simple, and it is a non-contact technique. Lu (2004), Peng and $\mathrm{Lu}$ (2006; 2007) investigated the use of diffuse reflectance and multispectral imaging techniques for the prediction of fruit firmness and soluble solids content (SSC) for apples.

Backscattering imaging with laser light technique is not an expensive method and can provide effective information to follow the tissue changes e.g. during drying process in case of apple, banana and bell pepper. Laser light source's wavelength of $670 \mathrm{~nm}$ was used to follow the drying period of banana (Romano et al., 2012a; Romano et al., 2008; Romano et al., 2011). Reported researches were able to find correlations between the validated methods and the used optical methods. Monte Carlo simulation was used to follow photon packages in kiwifruits and apple tissue in order to build inverse models for processing of diffuse reflection images (Baranyai and Zude, 2008, 2009). Qin and $\mathrm{Lu}$ (2009) used the Monte Carlo models to 
simulate light transport in apple tissue and they performed measurements with hyperspectral diffuse reflectance imaging system at the wavelength range of 500 to $1000 \mathrm{~nm}$. The light penetration depth into the fruit tissue was highly influenced by pigments and moisture content.

One of the most important postharvest quality parameters of fruits is the firmness. This property plays an important role during storage and in the decision making process for the consumer as well. Due to the numerous advantages of non-destructive methods, their role is increasing more and more. Two non-destructive firmness measurement methods (the acoustic response technique and the impact method) were used successfully in many researches. According to Felföldi and Fekete (2000) the acoustic method gives relevant information about the overall stiffness of the sample, and the impact method characterizes the firmness of the sample surface. By the help of these methods, the firmness related quality changes of fruits and vegetables can be detected. Molina-Delgado et al. (2009) found that the measurements based on impact method are highly sensitive to changes in turgidity of apple and suitable for the detection of differences between apple fruits from different harvest dates. Both the acoustic and the impact method were found to be capable of sensing firmness loss as induced by storage circumstances in case of apple and tomato (De Ketelaere et al., 2006). Acoustic impulse response represents more sensitivity to firmness changes than the M-T firmness test does during postharvest periods in case of pear (Gómez et al., 2005). They found the percentage change in the acoustic stiffness coefficient $(20.43 \%)$ after 4 weeks storage was larger than that of M-T firmness (6.4\%). Taniwaki et al. (2009a) used the acoustic vibration technique to follow the postharvest quality changes of two persimmon varieties and to determine their optimal eating ripeness.

Many researches reported that the acoustic and impact methods are found to be useful for classification. Ragni et al. (2010) developed a simple impact device supported by statistical analysis. This technique could be taken into consideration for on-line prediction of the flesh firmness of kiwi fruits. The acoustic and impact method was found to be suitable to separate the mango fruits into different maturity classes (Wanitchang et al., 2011). Diezma-Iglesias et al. (2006) found that the fusion of impact and acoustic tests offer good possibilities for the improvement of a sorting system for sensing firmness in case of peaches. Baltazar et al. (2008) used the acoustic and colorimeter sensor data in order to classify tomato fruits into different ripening stages. Schotte et al. (1999) used the acoustic impulse response technique to classify the tomatoes with different firmness and to study firmness changes of tomatoes during storage, and the influence of variety, 
producer, season, production method, maturity at the time of picking, and storage conditions.

The acoustic technique was tested not only in laboratory conditions but in-vivo measurements also. De Belie et al. (2000) found the acoustic method valuable for the monitoring of the firmness evolution of pears still on the tree and the determination of the optimum harvest date. Taniwaki et al. determined also the optimum harvest time in case of melon (2009c) and in case of pear (2009b) using a Laser Doppler vibrometer. The internal quality defect in watermelon can be detected with help of acoustic method (Diezma-Iglesias et al., 2004). Elbatawi (2008) successfully carried out measurements in order to detect internal quality defect (hollow heart) of potato tubers by the help of acoustic impact method.

The aims of our research work were the investigation of postharvest changes of pear samples during combined cold storage and shelf-life, the determination of quality changes mainly by non-destructive methods, the modeling of the changes of the non-destructive parameters (acoustic, impact stiffness coefficient, chlorophyll fluorescence parameters $\left[F_{v} / F_{m}\right.$, $\left.\left.F_{m} / F_{0}\right]\right)$, the determination of the rate of the changes of these parameters, and prediction of the quality characteristics by multivariate statistical analysis of the non-contact optical data.

\section{Materials and Methods}

Pear samples (Pyrus communis cv. Bosc kobak) were examined in this experiment. The fruits were harvested at the optimal harvest time. The test period lasted from the end of October to the middle of December, 2011. One hundred and twenty pear samples were measured during the measurement. Pear samples were stored at near to optimal storage temperature $\left(1.5 \pm 0.5{ }^{\circ} \mathrm{C}\right.$ with an average relative humidity of $\left.65 \pm 7 \%\right)$. Four times, with approximately two weeks intervals, 30 pear samples were withdrawn from the cool chamber for measurements. These samples were stored further at room temperature $\left(22 \pm 2{ }^{\circ} \mathrm{C}\right)$ for additional 10-14 days simulation of the conventional shelf storage conditions.

The changes of the total amount of 120 pieces were measured by nondestructive methods (laser scattering and chlorophyll fluorescence; acoustic impulse response and impact stiffness measurement methods) and by destructive methods (evaluation of starch index, $\mathrm{pH}$, Brix ${ }^{\circ}$ and titrimetric total acid content). The non-destructive measurements were carried out at the beginning of the experiment for the initial condition and later at an almost daily basis on 30 pear samples starting after the removal from cold 
storage and during shelf-life. In the presented figures and diagrams the day 0 represents the start of the cold storage experiment. The first removal from cold storage and the beginning of the first shelf-life period started on the $13^{\text {th }}$ day.

\subsection{Optical methods}

Laser scattering measurement:

Laser imaging system was assembled for this research. Image acquisition took place in a dark box in order to enhance signal to noise ratio and avoid influence of foreign light sources. The machine vision system was based on a high performance monochromatic CCD IP camera (Photon Focus MV1-D1312 Gigabit Ethernet Series, gray scale resolution of 12 bit, max. spatial resolution of $1312 \times 1082$ pixels, spectral sensitivity from $320 \mathrm{~nm}$ to $1080 \mathrm{~nm}$ ) with a L-SV-L5014MP megapixel lens of fixed focus, optimized for visual and near infrared applications. Seven solid-state laser diode modules emitting at seven different spectral bands $(532,635,650,780,808,850,1064$ $\mathrm{nm}$ ) were used. All laser light beams were adjusted to $15^{\circ}$ incident angle in order to inject laser beam into the fruit tissue (Fig. 1). Each laser light beam had almost the same focus point on the sample surface within $2 \mathrm{~mm}$ distance depending on the curvature. The camera was positioned vertically above the sample. After the laser beam entered into the fruit tissue, surface area surrounding the incident point got illuminated by diffuse reflectance. This illuminated area was scanned and intensity values were calculated with radial averaging relative to the incident point. Threshold of the $50 \%$ intensity level was used to segment illuminated area and facilitate automatic detection of incident point. The location of the incident point was identified by weighted average. Full width at half maximum (FWHM), and inflection point $(I P)$ of the intensity profile were calculated. The slope of the logarithm intensity profiles was calculated as well (SLOPE). Measurements were carried out at the two directly opposite sides of each pear sample at the equatorial part. The initial laser scattering data were measured at the beginning of the experiment for all the 120 samples. Measurements were done at an almost daily basis on 30 pear samples starting after each removal from cold storage (day 13, 27, 39 and 53) and during shelf-life.

Chlorophyll fluorescence measurements:

Chlorophyll fluorescence measurements were carried out by Monitoring PAM - Multi-channel Chlorophyll Fluorometer (MONI-PAM, Heinz Walz GmbH, Germany) in order to determine the change of characteristic chlorophyll fluorescence parameters (Fig. 2). 


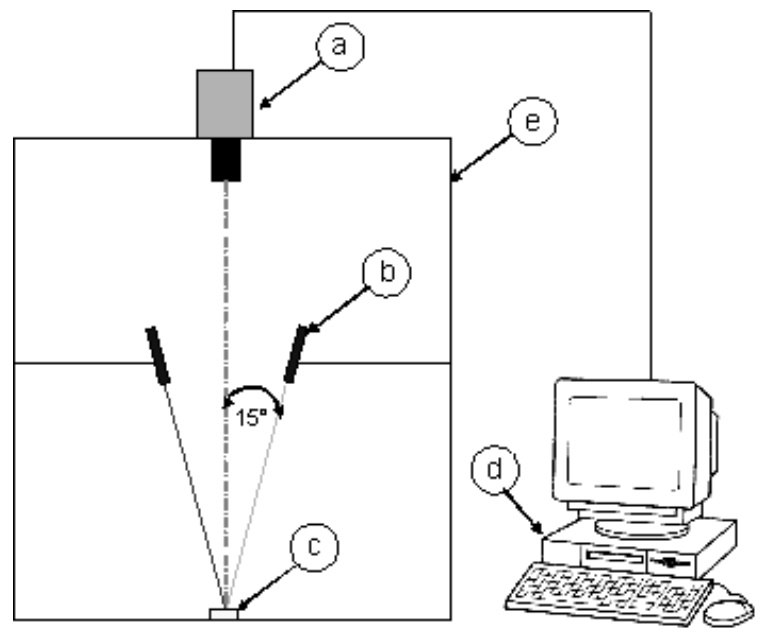

Fig. 1. Schematic view of the imaging system for measuring light backscattered from the sample. a: CCD IP camera with lens; b: laser module; c: sample (pear); d: computer with a gigabit Ethernet port for data acquisition and processing; e: dark box

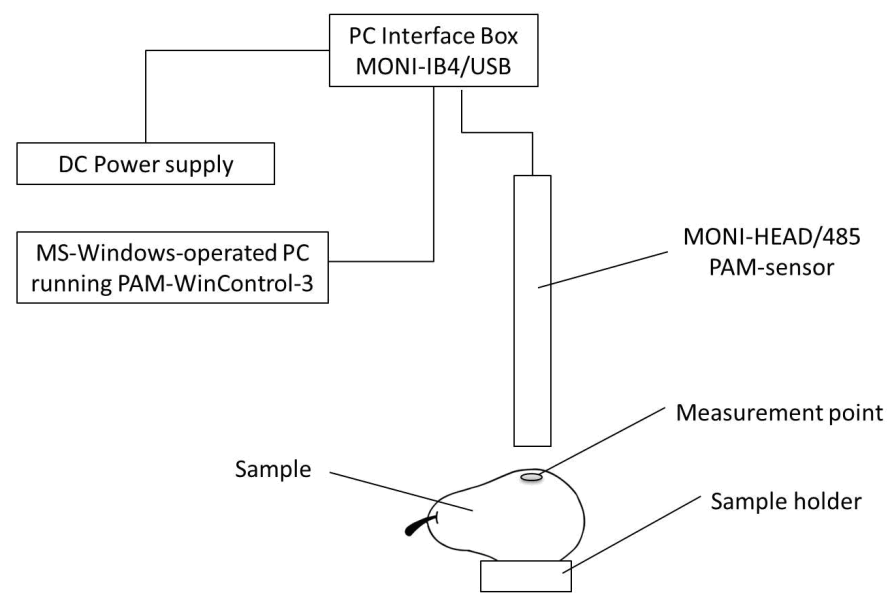

Fig. 2. The schematic view of the measurement carried out by the use of the Monitoring PAM - Multi-channel Chlorophyll Fluorometer

The measured parameters were the minimum and the maximum fluorescence $\left(F_{0}\right.$ and $\left.F_{m}\right)$. The variable fluorescence $\left(F_{v}=F_{m}\right)$ and $F_{v} / F_{m}$ ratio (i.e. the maximum photochemical efficiency, referring to the tissue's photosynthetically active chlorophyll content) furthermore the $F_{m} / F_{0}$ parameter were calculated from the measured fluorescence data (Fig. 3). 


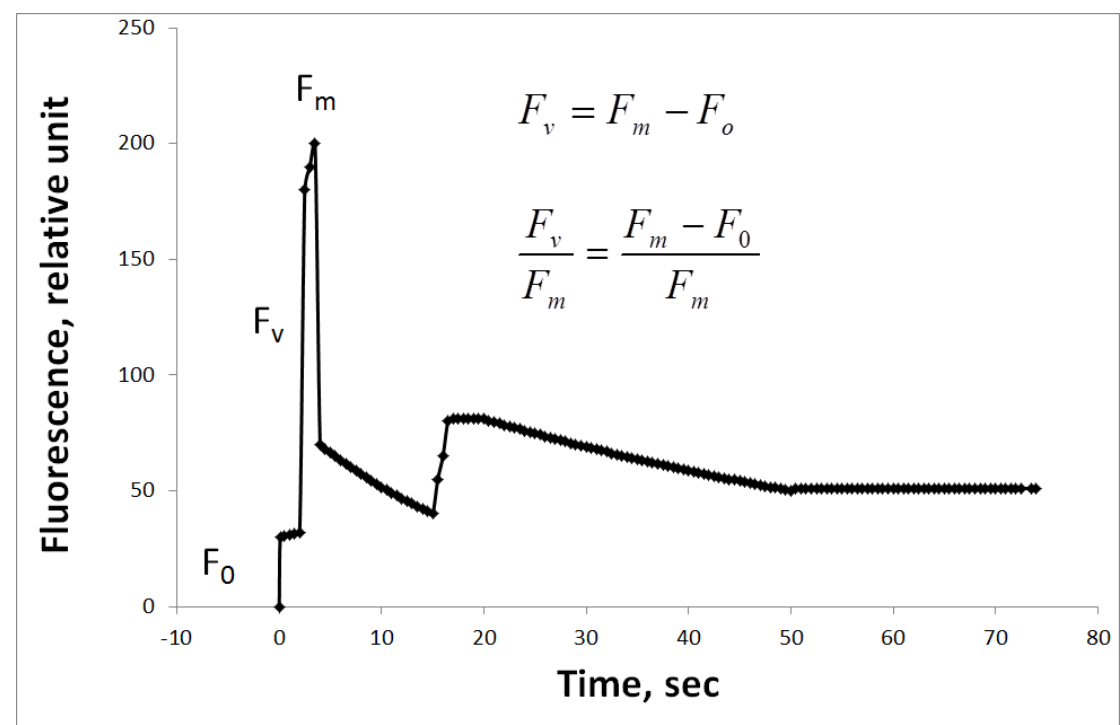

Fig. 3. The characteristic points of a chlorophyll fluorescence curve

Data collection was carried out by PAM WinControl-3 (Heinz Walz $\mathrm{GmbH}$, Germany). The pear was placed on the sample holder at about 10 $\mathrm{mm}$ distance under the MONI-HEAD/485 PAM-sensor. Fluorescence data collections were carried out at the same two positions per each sample as it was done by laser scattering data collection.

\subsection{Non-destructive texture measurements}

The textural changes were measured by acoustic impulse response technique and impact method. Acoustic impulse response technique:

The samples were tapped lightly on the equator with a wooden stick. The pear's acoustic response was collected by microphone located under the cushioning sample holder. The microphone's output was recorded by a sound card in a PC-compatible computer (Fig. 4). Custom Fast Fourier Transform software was used to analyze the recorded acoustic response. From the resulting frequency spectrum the first resonance frequency was selected (Chen and De Baerdemaeker, 1993; Schotte et al., 1999). There is significant connection between the peak (characteristic) frequency of the acoustic signal and the sample's firmness, but the frequency of the vibration depends on the size, shape and texture of the product (Chen and De Baerdemaeker, 1993; Zsom-Muha and Felfödi, 2007). The characteristic 
frequency and the sample mass were used to calculate the firmness coefficient (Schotte et al., 1999; Valente et al., 2009):

$$
S=f^{2} \cdot m^{2 / 3}
$$

where

- $\quad$ : acoustic stiffness coefficient, $10^{6} \mathrm{~Hz}^{2} \mathrm{~g}^{2 / 3}$,

- $f$ : characteristic frequency of the sample, $\mathrm{Hz}$,

- $m$ : sample mass, $g$.

The mass of the sample was measured with a precision balance.

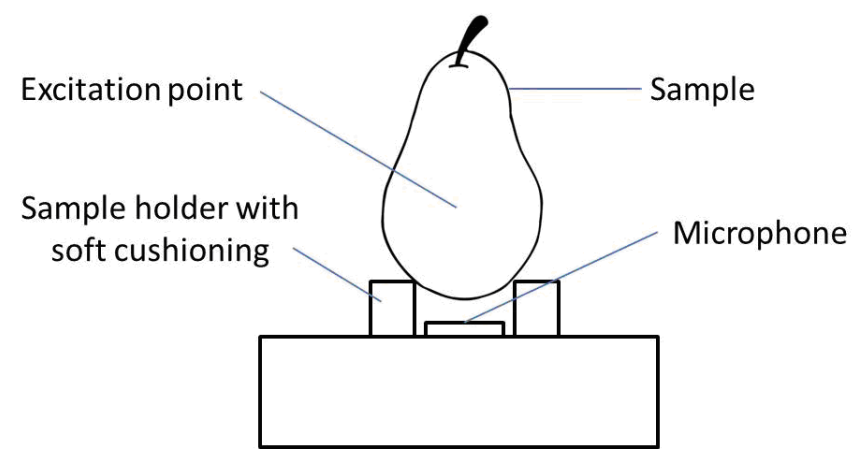

Fig. 4. Basic setup of acoustic method

Impact method:

The impact method is based on the observation that the impact hammer's deceleration or the force on the rigid surface during impact of the fruit depends on the sample's firmness and elasticity (Delwiche et al., 1987; Felföldi and Fekete, 2000). The measuring system consists of an impact hammer with a changeable mass and a built-in piezoelectric accelerometer, an electronic signal converter and a dynamic signal analyzer recording and displaying the voltage signal of the accelerometer. Time and voltage differences between initial and maximum point of the curve were determined by a special program (developed by Physics and Control Department, Faculty of Food Science, Szent István University, Hungary). The sample's firmness is characterized by the impact stiffness coefficient (Felföldi, 1996):

$$
D=1 / \Delta T^{2}
$$

where

$$
\begin{gathered}
-D \quad-\text { impact stiffness coefficient, } \mathrm{ms}^{-2}, \\
-\Delta T \quad \text { - time difference between initial and maximum point of the } \\
\text { curve, ms. }
\end{gathered}
$$


The impact stiffness of pear was measured at four points on the equator. The average of these four points determined the impact stiffness of the surface.

\subsection{Destructive measuring methods}

Destructive tests, as starch index evaluation, measurement of $\mathrm{pH}$ and total water soluble solid content (TSS, Brix ${ }^{\circ}$ ) and the determination of titrimetric total acid content, were carried out after the withdrawal of each sample batch of 30 pears from cold storage for shelf-life storage purposes (5 pieces) and at the end of the shelf-life ( 25 pieces) storage period.

Starch index: In order to determine the starch index, iodine-potassium iodide solution was used (composition: $\lg K J+\lg J+100 \mathrm{ml}$ distilled water). The pears were cut along the equator, and the samples were immersed in the iodine solution. After few minutes the starch content of the sample was dyed blue. Comparing to a starch scale standard (ranging 1-10, where 1 is the highest level and 10 is the lowest level starch content) the starch index of the sample was determined by fruit postharvest expert.

The $\mathrm{pH}$ measurements were carried out by a handheld Testo type 206 pH meter (Testo SE \& Co. KGaA, Germany) equipped with a combination of $\mathrm{pH}$ penetration tip and temperature probe. The $\mathrm{pH}$ value was measured at 4 points near the core and 4 points near the peel (see Fig. 5). The average of the 4-4 points was used to the analysis.

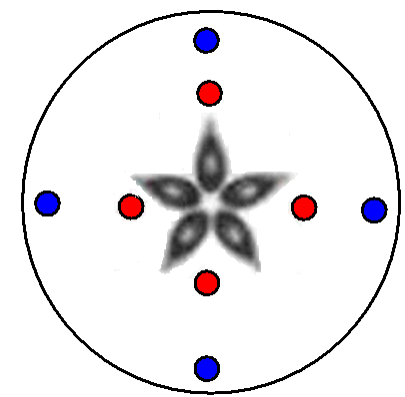

Fig. 5. The locations of $\mathrm{pH}$ measurements

Total soluble solids content $\left(\right.$ Brix $\left.^{\circ}\right)$ :

After the destructive tests fruit flesh juice was squeezed and measured by an ATAGO-PR-1 type refractometer (Atago Co Ltd., Japan) (4 points per sample). The average of the 4 Brix $^{\circ}$ value was used for the evaluations. 
Titrimetric total acid content:

The flesh of the peeled samples was mixed and filtered. The pear juice $\left(20 \mathrm{~cm}^{3}\right)$ was diluted with distilled water to $100 \mathrm{~cm}^{3}$ and homogenized. Twenty $\mathrm{cm}^{3}$ of this solution was titrated by $0,1 \mathrm{n} \mathrm{NaOH}$ in the presence of phenolphthalein $\mathrm{pH}$ indicator until the solution's color changed to pale pink. Three repetitions were done. Titrimetric total acid content (\%) was calculated as TTA $(\%)=V_{d} * f * E * 25$, where $V_{d}$ is the decrease of $0,1 \mathrm{n}$ $\mathrm{NaOH}$ solution $\left(\mathrm{cm}^{3}\right), f$ is the factor of the $0,1 \mathrm{n} \mathrm{NaOH}$ solution, $E$ is the acid equivalent $(0.067 \mathrm{~g}$ for malic acid).

For data conversion Microsoft Office Excel ${ }^{\circledR}$ and for statistical analysis SPSS Statistics ${ }^{\circledR}$ version 17 programs were used. For the visualization of the result of the destructive measurements the mean values with the $95 \%$ confidence interval of the data are shown. The open source software of $\mathrm{R}$ (version 2.13, R Foundation for Statistical Computing, Vienna, Austria) was used to perform multivariate statistical analysis, produce summary reports and charts in case of the laser scattering data analysis. The Solver part of Excel program was used to calculate Storage Time Equivalent Values and for fitting the predicted models.

Multivariate method (PLS with leave-one-out cross validation) was used to build prediction model for the non-destructive quality parameters based on non-contact laser scattering method. The daily average values of the scattering data were used in the further analysis, because of the high variability in the individual data of the tested samples.

The error associated with the results of the regression model was defined by the root mean square error of calibration (RMSEC) or validation $(R M S E V)$. Robust parameter design (RPD) index was determined, to evaluate the goodness of the models Eq. (3). It shows how many times the standard deviation of the measured parameter (STD) is higher than the error of validation:

$$
R P D=S T D / R M S E V .
$$

\section{Results and Discussion}

Figure 6 shows the results of the destructive measurements. No significant changes can be observed in case of the titrimetric total acid content, Brix ${ }^{\circ}$, and $\mathrm{pH}$ parameters (measured near the peel and on the inner part) during the measurement period. Presumably, the reason for these phenomena is that the measured changes were lower then the variability between the individual pear samples. According to the starch degradation process during postharvest ripening and shelf-life, the starch index increase clearly represents the natural process of starch degradation (Fig. 6e). 


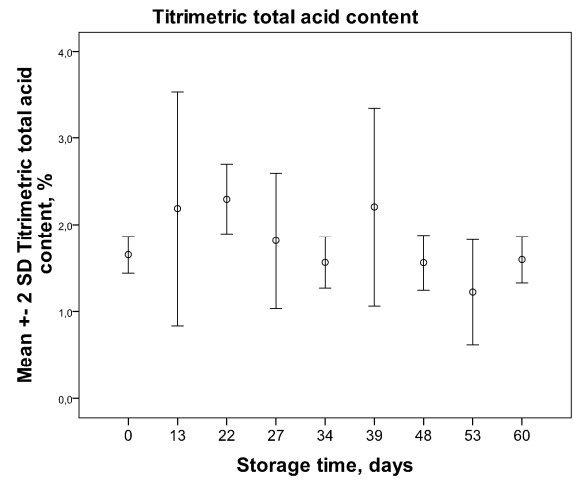

(a)

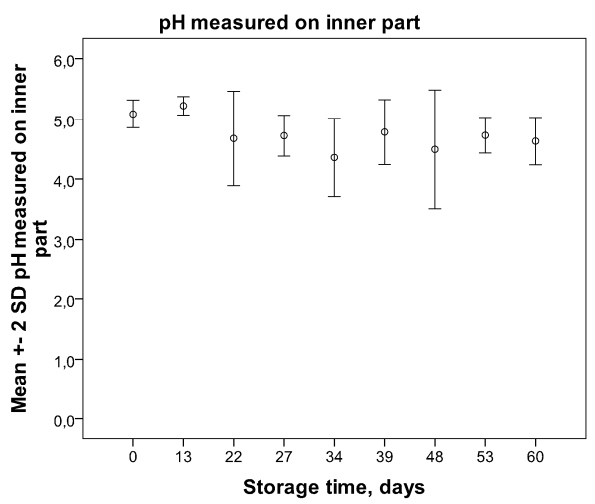

(c)

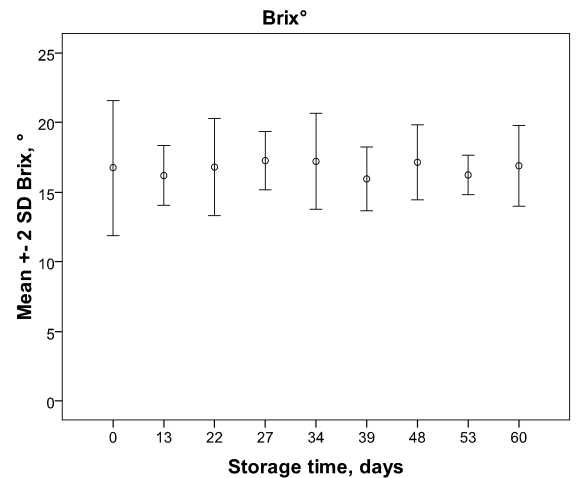

(b)

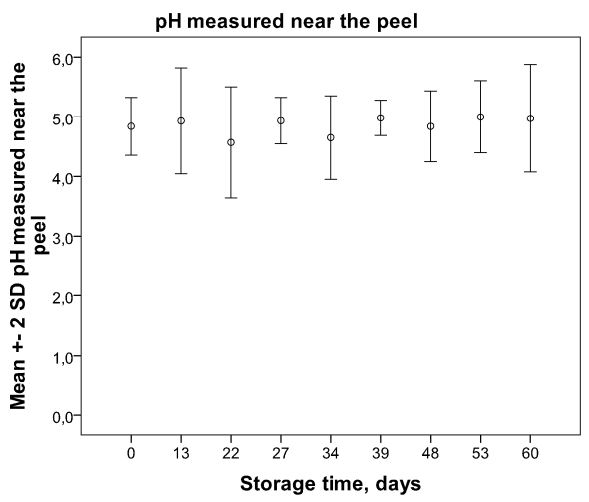

(d)

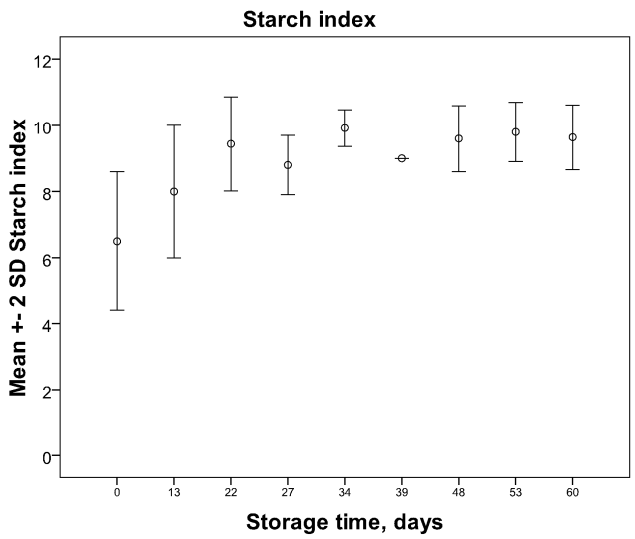

(e)

Fig. 6. The changes of the titrimetric total acid content (a), Brix ${ }^{\circ}$ value (b), $\mathrm{pH}$ (measured on inner part) (c), (measured near the peel) (d), starch index (e) during the storage period 
Although the changes of the destructive parameters cannot be detected significantly during the storage periods, in case of the non-destructive texture parameters clear and obvious changes were observed as follows.

The shelf storage experiments after different cool storage periods (13, 27,39 , and 53 days, respectively) resulted in a very special pattern in the characteristics of the samples, e.g. in the mass (Fig. 7) or in the acoustic stiffness coefficient (Fig. 8). The different storage conditions caused obviously different mass loss rates, and conclusively different mechanical changes in the pear samples.

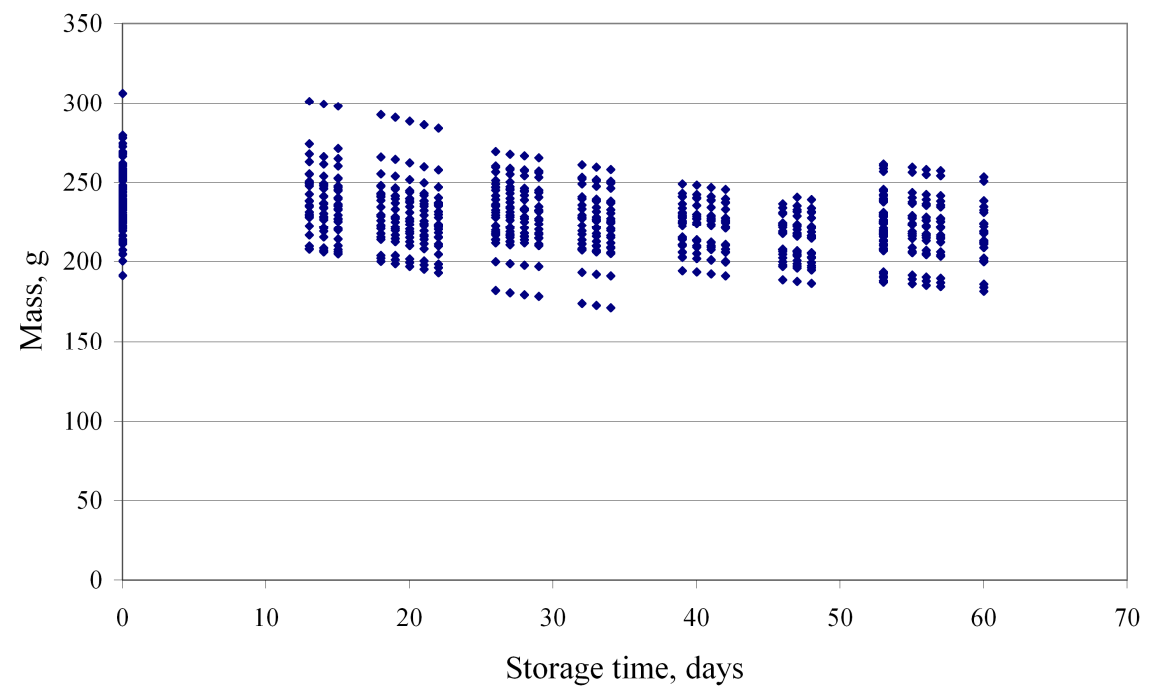

Fig. 7. The measured mass data reflecting the mass change of the pear samples vs. storage time

In order to model the physical changes (e.g. the softening process) of the samples, it is reasonable to find the equivalency between these two storage types (cool and room), to find a time-scale transformation, resulting in a monotonous change in the target parameter.

Taking into account the mass loss, as a characteristic change of the samples during the storage, we can suppose that the mass loss rate of a sample in a given condition is proportional to its actual value (the mass change can be described by a first-order differential equation), conclusively, the change can be described by an exponential function vs. time. The main difference between the storage conditions can be represented by the time constant $(\tau)$ of the describing functions: 


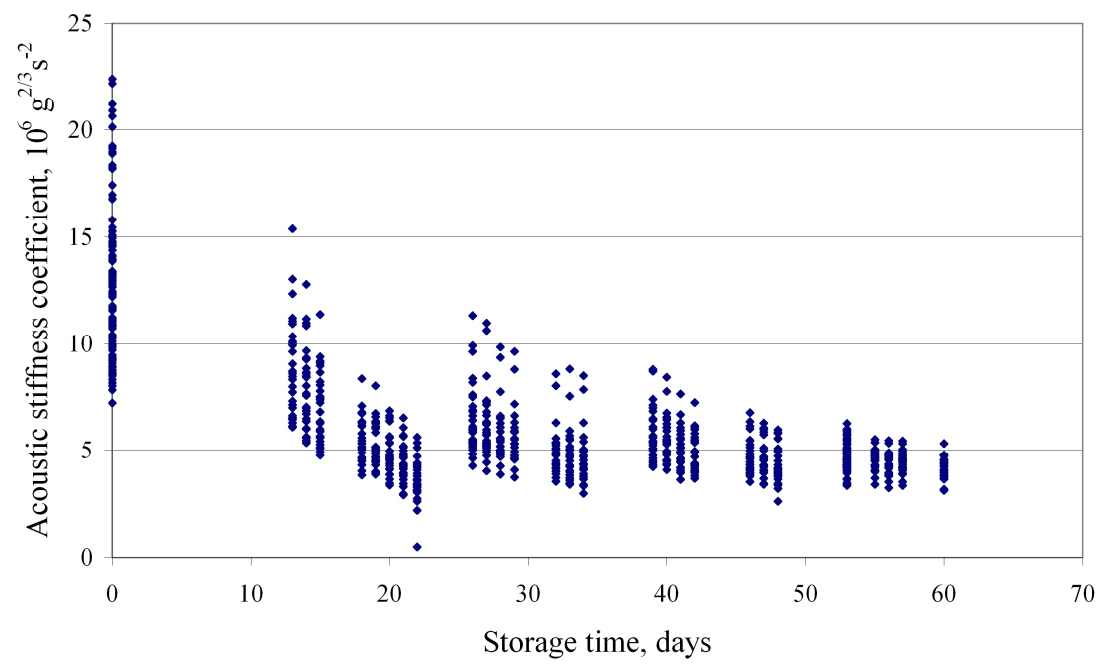

Fig. 8. The calculated acoustic stiffness coefficient's change of the pear samples vs. storage time

In cool chamber:

$$
m_{\text {cool }}=\left(m_{0}-m_{\infty}\right) \cdot e^{-\frac{t_{\text {cool }}}{\tau_{\text {cool }}}}+m_{\infty}
$$

During room storage:

where

$$
m_{\text {room }}=\left(m_{0}-m_{\infty}\right) \cdot e^{-\frac{t_{\text {room }}}{\tau_{\text {room }}}}+m_{\infty}
$$

$m_{0}$ : starting value of the sample mass

$m_{\infty}$ : final value of the sample mass after very long storage

$\tau$ : time constant of the mass loss process After a combined storage of

$$
\begin{gathered}
t=t_{\text {cool }}+t_{\text {room }} \\
m=\left(m_{\text {cool }}-m_{\infty}\right) \cdot e^{-\frac{t_{\text {room }}}{\tau_{\text {room }}}}+m_{\infty}=\left(\left(m_{0}-m_{\infty}\right) \cdot e^{-\frac{t_{\text {cool }}}{\tau_{\text {cool }}}}+m_{\infty}-m_{\infty}\right) \cdot e^{-\frac{t_{\text {room }}}{\tau_{\text {room }}}}+m_{\infty} \\
m=\left(m_{0}-m_{\infty}\right) \cdot e^{-\left(\frac{t_{\text {cool }}}{\tau_{\text {cool }}}+\frac{t_{\text {room }}}{\tau_{\text {room }}}\right)}+m_{\infty}
\end{gathered}
$$

If $\tau_{\text {cool }}=c \cdot \tau_{\text {room }}$

the (6) equation can be written in a form:

$$
m=\left(m_{0}-m_{\infty}\right) \cdot e^{-\left(\frac{t_{\text {cool }}+c \cdot t_{\text {room }}}{\tau_{\text {cool }}}\right)}+m_{\infty}
$$


According to our approach, the changes can be transformed to a common base, introducing the Storage Time Equivalent Value (STEV), the calculated virtual storage time:

where

$$
\mathrm{STEV}=t_{\text {cool }}+c * t_{\text {room }}
$$

$t_{\text {room }}:$ the time period at room temperature

$t_{\text {cool }}$ : the time period at cool storage chamber

$c$ : multiplicative factor, presenting the ratio of the mass loss rate during the room storage to the rate in the cool chamber.

The Solver function of the Microsoft Excel was used to fit the (7) function to the percentage values of the sample mass (mass of every individual sample was compared to its initial values at the beginning of the experiment) (Fig. 9). Daily average values were used in the model to avoid the disturbing effect of the high variability of the lot. The sum of the squared difference between the measured and calculated percentage mass values was minimized by the Solver, modifying the value of the parameters: $m_{\infty}, \tau_{\text {cool }}$ and " $c$ ".

Percentage mass loss - daily average values

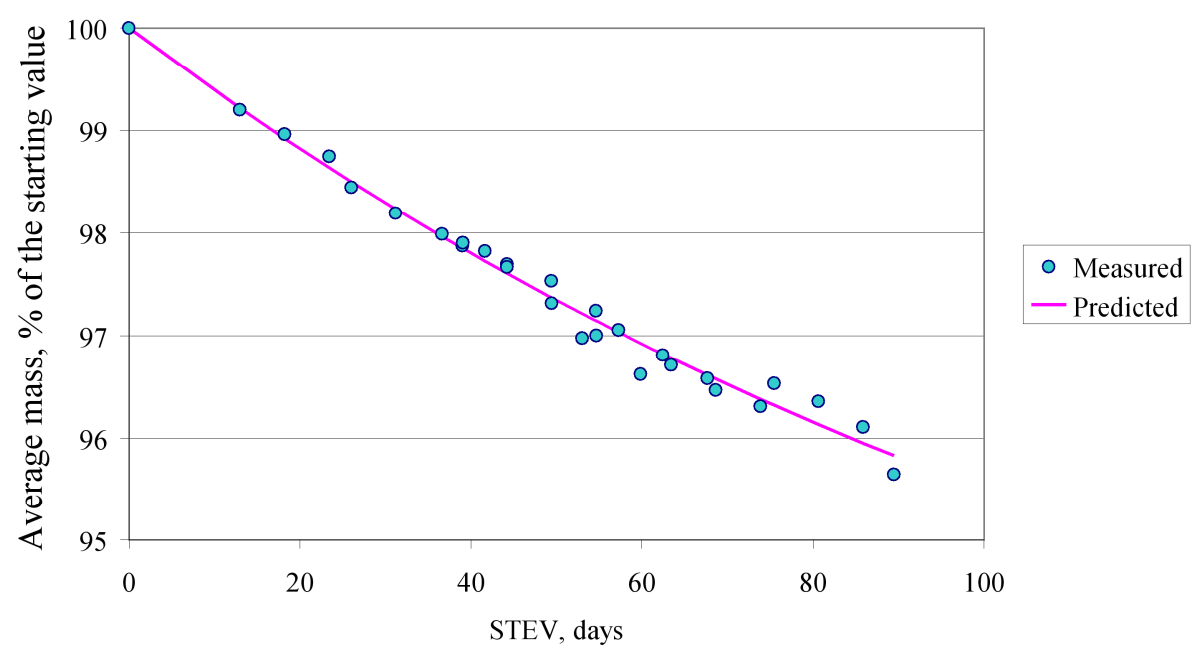

Fig. 9. Change of average mass (\% of the initial mass value) of the pear samples versus STEV

For the given data set, the value of the $c$ multiplicative factor was found to be $c=5.20$ (other best fitting parameters were: $m_{\infty}=91.2 \%, \tau_{c o o l}=26.6$ days, $\left.r^{2}=0.985\right)$. 
This time-scale transformation was determined based on mass-loss analysis, conclusively it can be applied directly only for mass change modeling, or to model the change of parameters, depending first of all on the mass loss of the samples, such as the mechanical characteristics (stiffness, hardness).

Figure 10, illustrating the acoustic stiffness coefficient (daily average values) versus the virtual storage time (STEV) confirms our assumption, that the stiffness change of the samples is determined rather by the mass loss, than other (e.g. physiological) processes within the investigated time period. Exponential model was fitted to the measured stiffness values vs. STEV ("Predicted" line on Fig. 10). The model parameters, resulting in the best fit, were determined by Microsoft Excel, Solver function as well:

Acoustic stiffness coefficient: $S=(12.86-4.19) \cdot e^{-\frac{S T E V}{21.0}}+4.19\left(r^{2}=0.989\right)$

For practical use, the model can be applied to predict the mechanical stage (stiffness) of the pear (cv. Bosc Kobak) after the storage (cool storage, shelf storage or any combination of these two storage types) or to calculate the appropriate storage time (and method) to reach the desired value of the mechanical stage.

Acoustic stiffness coefficient - daily average values

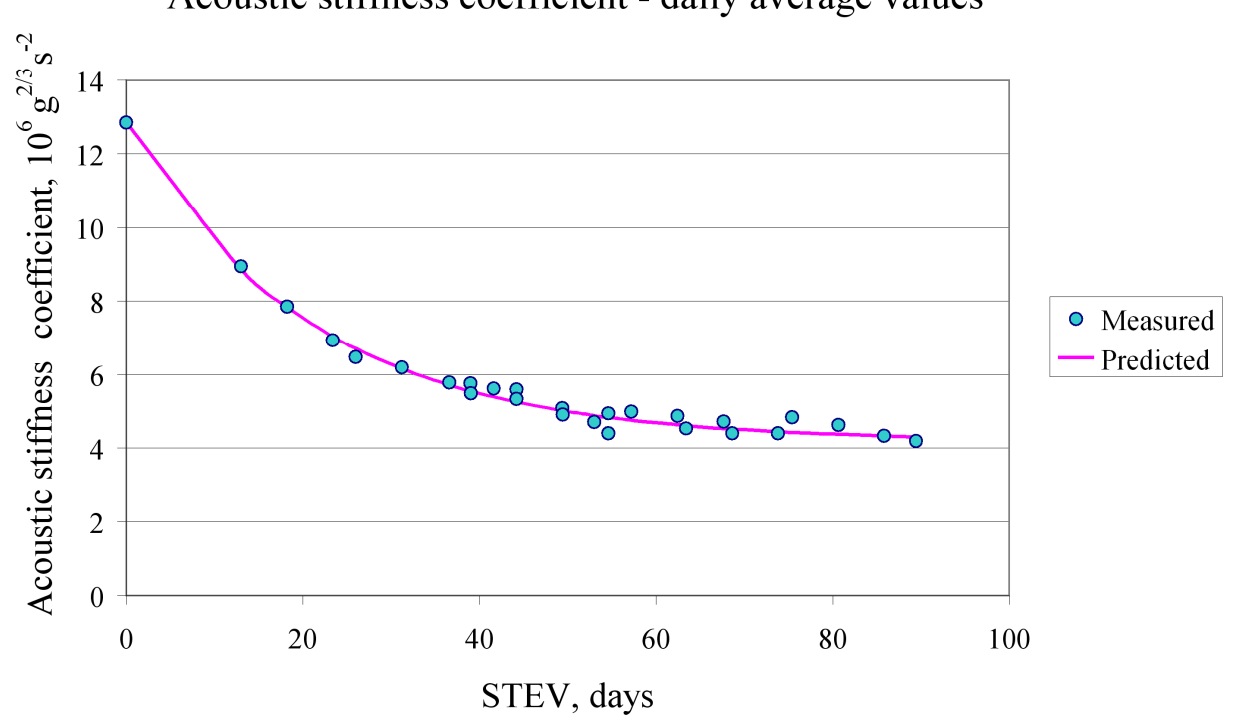

Fig. 10. Change of acoustic stiffness coefficient (daily average values) of the pear samples vs. STEV 
Analysis of the impact stiffness coefficient (surface firmness) vs. STEV resulted in similar trend (Fig. 11), however, with much less determination coefficient due to the high variability of the samples in this characteristic and because of the smaller reproducibility of the impact method.

Impact stiffness coefficient - daily average values

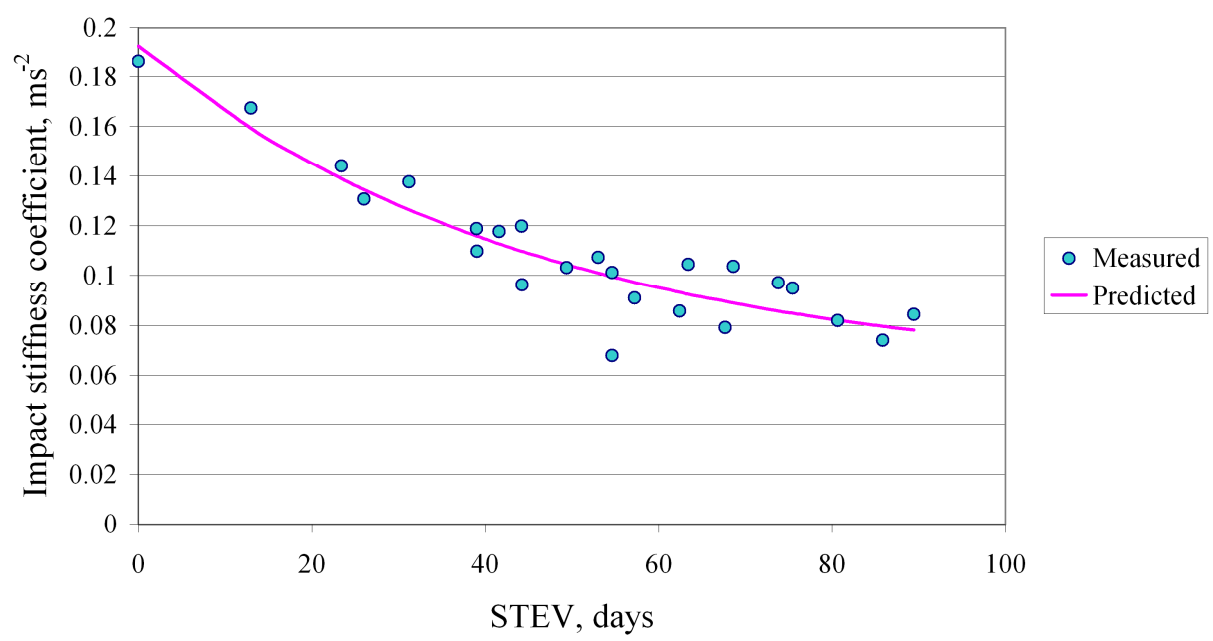

Fig. 11. Change of impact stiffness coefficient (daily average values) of the pear samples vs. STEV

Impact stiffness coefficient: $D=(0.192-0.059) \cdot e^{-\frac{S T E V}{45.8}}+0.059 \quad\left(r^{2}=0.851\right)$

Comparing the two time constants of the fitted models, great difference can be observed between the two measuring methods (acoustic stiffness measurement: 21.0 days and impact method: 45.8 days). Taking into consideration the percentage mass loss, this relation refers to the higher sensitivity of the acoustic stiffness measurement method related to the impact firmness method.

With the help of the STEV data (related to the percentage mass loss of the sample) the change in the chlorophyll fluorescence parameters can be modeled and predicted as well. Firstly, the change of the generally used chlorophyll fluorescence indicator, $F_{v} / F_{m}$ was analyzed. Taking into consideration the results of Bron et al. (2004), as the $F_{m} / F_{0}$ values were stated as a reliable indicator for classification into maturity stages, the change of the $F_{m} / F_{0}$ parameter was analyzed as well. The changes of the $F_{v} / F_{m}$ and $F_{m} / F_{0}$ values show a similar trend as it was observed in case of nondestructive texture measurements. In case of the two chlorophyll fluorescence parameters, the changes can be approximated with an 
exponential trend as well. Figure 12 and Figure 13 show the changes of the $F_{v} / F_{m}$ and $F_{m} / F_{0}$ values vs. STEV and the fitted model, respectively.

\section{$\mathrm{F}_{\mathrm{v}} / \mathrm{F}_{\mathrm{m}}$ - daily average values}

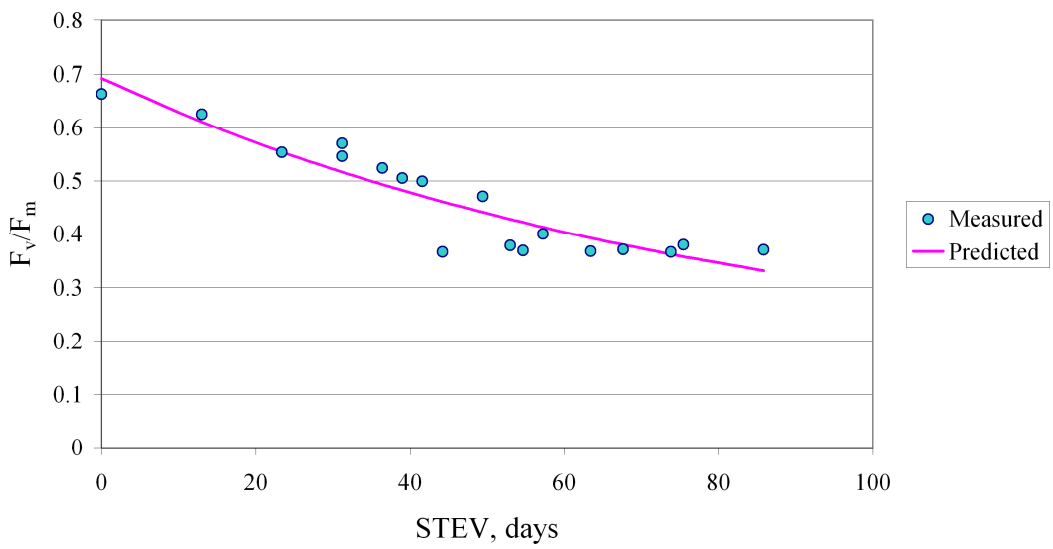

Fig. 12. Change of $F_{v} / F_{m}$ value (daily average values) of the pear samples vs. STEV

The equation of the predicted model is the following in case of $F_{v} / F_{m}$ parameter:

$$
F_{v} / F_{m}: \quad F_{v} / F_{m}=(0.692-0.131) \cdot e^{-\frac{\text { STEV }}{83.4}}+0.131 \quad\left(\mathrm{r}^{2}=0.830\right)
$$

$\mathrm{F}_{\mathrm{m}} / \mathrm{F}_{0}$ - daily average values

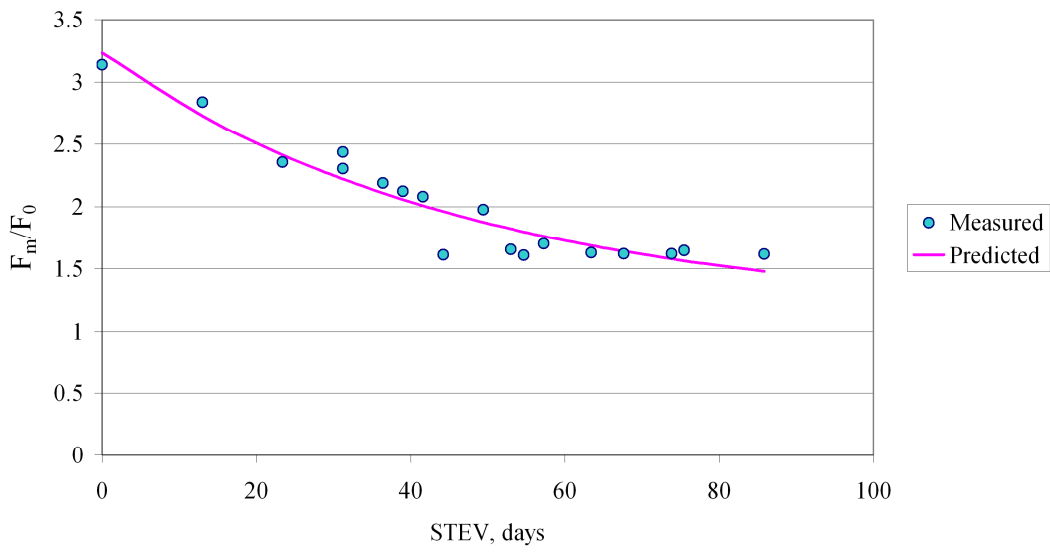

Fig. 13. Change of $F_{m} / F_{0}$ value (daily average values) of the pear samples vs. STEV 
The changes of the $F_{m} / F_{0}$ vs. STEV can be estimated by the following equation:

$$
F_{m} / F_{0}: \quad F_{m} / F_{0}=(3.23-1.15) \cdot e^{-\frac{S T E V}{47.1}}+1.15 \quad\left(\mathrm{r}^{2}=0.904\right)
$$

Having compared the change of $F_{v} / F_{m}$ and $F_{m} / F_{0}$ chlorophyll fluorescence parameters and the fitted models, it can be stated that the determination coefficient of $F_{m} / F_{0}(0.904)$ suggests much closer relation between the measured and predicted data vs. STEV than $F_{v} / F_{m}(0.830)$. Taking into account the two time constants of the two predicted models, the lower value of $F_{m} / F_{0}$ (47.1 days) suggests higher sensitivity of this chlorophyll fluorescence parameter to represent the measured changes than the $F_{v} / F_{m}$ (83.4 days) parameter generally used in the literature.

Seven laser modules were applied during the measurements. The PLS prediction based on all data was performed in different combinations. After the data evaluation two lasers ( 635 and $780 \mathrm{~nm}$ ) were chosen providing the highest scores in the prediction. The PLS prediction of mean of acoustic stiffness, impact stiffness coefficient, $F_{v} / F_{m}$ and $F_{m} / F_{0}$ values by mean of SLOPE, IP and FWHM parameters was performed (Fig. 14). The determination coefficient $\left(\mathrm{R}^{2}\right)$ and RPD statistical parameters were used to characterize the quality of the PLS model. The best prediction was obtained in case of the $F_{m} / F_{0}$ with $\mathrm{R}^{2}=0.96$ and $\mathrm{RPD}=5.37$ (Fig. 14c).

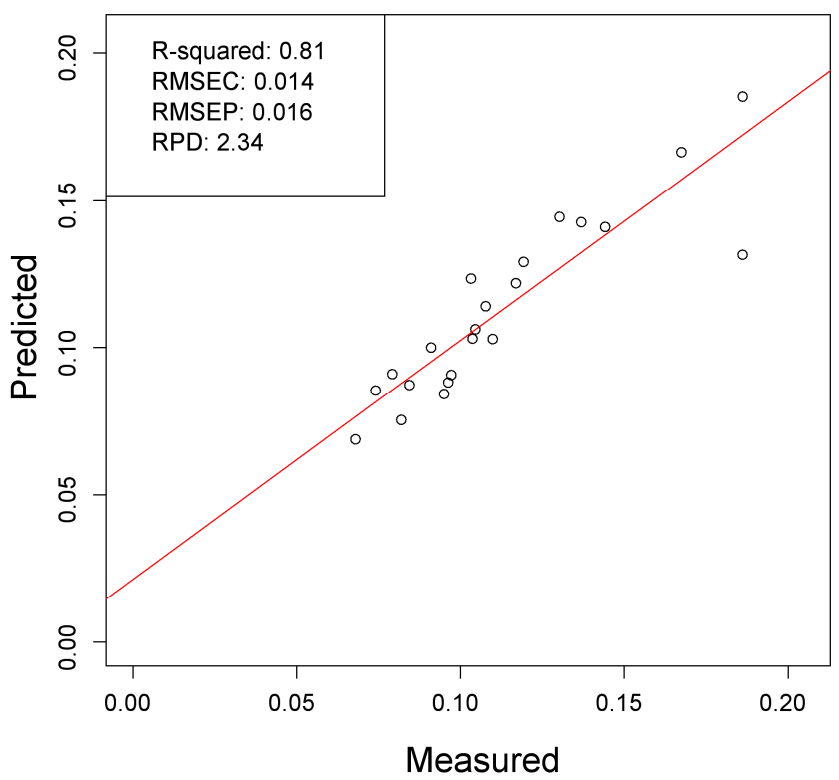

(a) 


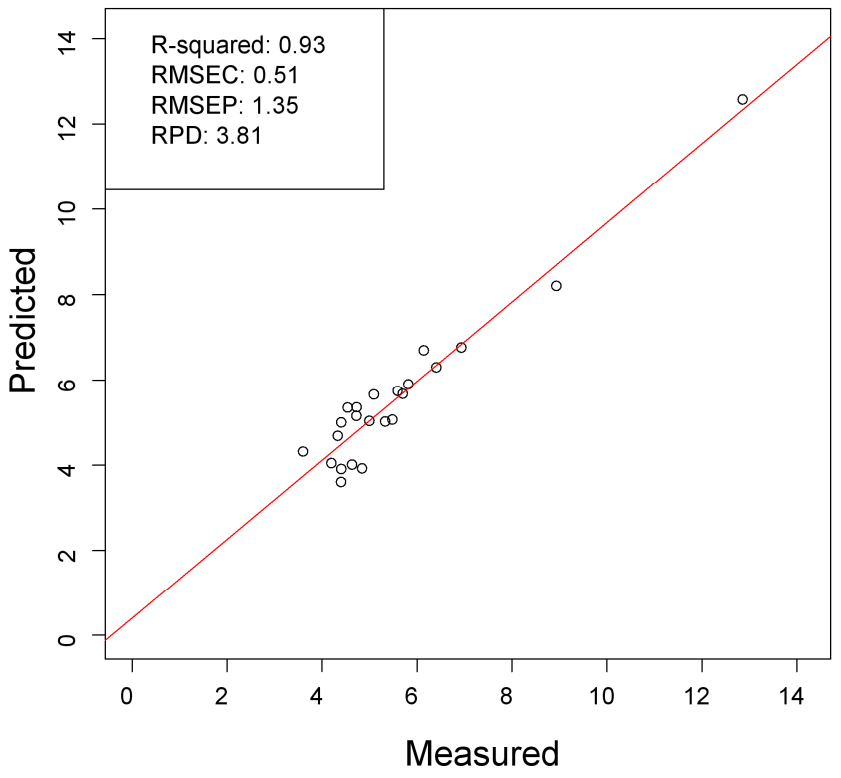

(b)

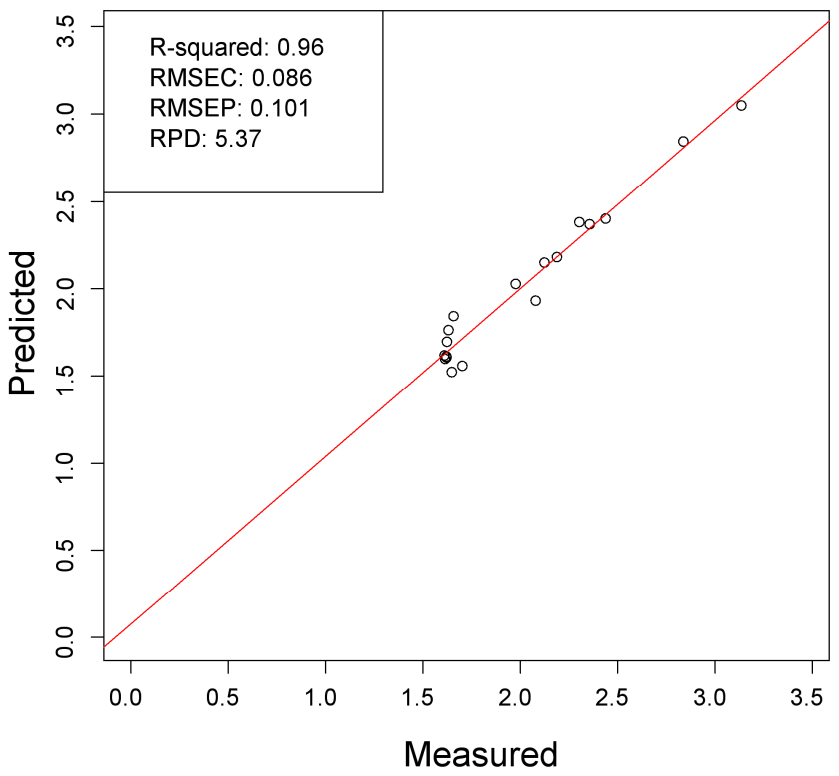

(c) 


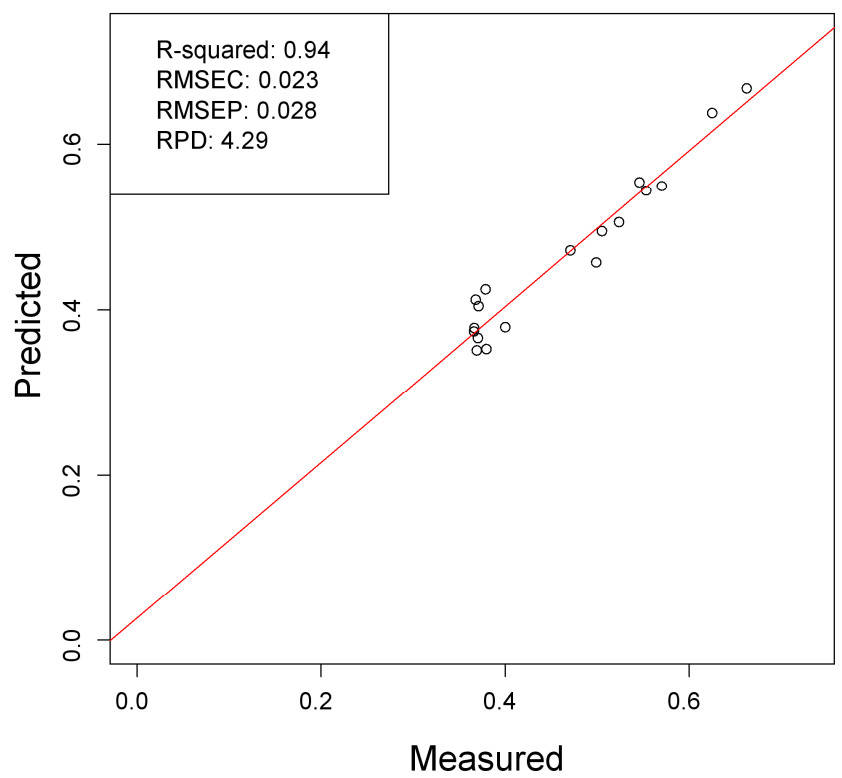

(d)

Fig 14. PLS prediction of impact (a), acoustic stiffness coefficient (b), $F_{m} / F_{0}$ (c) and $F_{v} / F_{m}$ (d) by SLOPE, IP and FWHM parameters measured by lasers at 635 and $780 \mathrm{~nm}$ wavelengths

\section{Conclusions}

The results of the destructive measuring methods (titrimetric total acid content, Brix $^{\circ}$ and $\mathrm{pH}$ ) showed no significant changes during the consecutive cold storage and shelf life periods.

According to our approach, in order to find the equivalency between the two storage types (cool and room), the Storage Time Equivalent Value $(S T E V)$, as the calculated virtual storage time was introduced. This timescale transformation resulting in a monotonous change in the measured non-destructive parameters was based on mass-loss analysis. The nondestructive texture parameters, as acoustic and impact stiffness coefficients and chlorophyll fluorescence characteristics $\left(F_{v} / F_{m}, F_{m} / F_{0}\right)$ showed significant change during the postharvest cold storage and shelf-life periods and their change were analyzed versus STEV. Exponential models were fitted to the measured and calculated data. Taking into account the percentage mass loss versus STEV, the time constant (representing the rate of change) of the acoustic, the impact stiffness coefficient and the chlorophyll fluorescence parameters $\left(F_{m} / F_{0}, F_{v} / F_{m}\right)$ were 21.0, 45.8, 47.1 and 
83.4 days, respectively. The lower the value of this time constant, the faster the change of the given quality parameter related to the percentage mass loss. These data represent the sensitivity of the given non-destructive method and the rate of the observed and predicted changes of the examined quality parameter. The higher determination coefficient of $F_{m} / F_{0}(0.904)$ suggests much closer relation between the measured and predicted data versus STEV than $F_{v} / F_{m}(0.830)$. Obviously, the "rate parameter" is depending on the storage conditions of the two different storage periods, so the model parameters are applicable only to the given experiment; however, the approach applied can be generalized.

Seven laser modules in the wavelength range of 532-1064 $\mathrm{nm}$ were used during the experiments. However, from practical point of view it is reasonable to reduce the number of the lasers to facilitate deployment of this non-contact method as in-vivo technology. Two lasers were chosen providing the best scores in the PLS prediction. The prediction of mean of acoustic stiffness, impact stiffness coefficient, $F_{v} / F_{m}$ and $F_{m} / F_{0}$ values was performed by mean of SLOPE, IP and FWHM parameters extracted using lasers at 635 and $780 \mathrm{~nm}$ wavelengths. The best prediction was obtained in case of the $F_{m} / F_{0}$ with $\mathrm{R}^{2}=0.96$ and $\mathrm{RPD}=5.37$.

According to the results, in agreement with the literature, SLOPE value can refer to the physical state of pear tissue, the FWHM and IP values can be related to the absorption. It is obvious that the chlorophyll content, water content and the firmness of pear suffered decay during storage. Therefore it may be concluded that the laser at $635 \mathrm{~nm}$ can be suitable to detect the decrease of chlorophyll content. The laser at $780 \mathrm{~nm}$ might be suitable to monitor the decrease of moisture content similarly to the study of Romano et al. (2012b).

The encouraging PLS results of the non-contact optical (laser scattering) method to predict the change of the physical characteristics during the storage offers the possibility to develop a simplified handheld instrument and method for quick quality evaluation of the stored fruits.

\section{Acknowledgements}

This work was supported by TÁMOP 4.2.1/B-09/1/KMR/-2010-0005 and TÁMOP 4.2.2/B-10/1-2010-0023. 


\section{References}

Baltazar, A., Aranda, J.I., González-Aguilar, G., 2008. Bayesian classification of ripening stages of tomato fruit using acoustic impact and colorimeter sensor data. Computers and Electronics in Agriculture 60, 113-121.

Baranyai, L., Zude, M., 2008. Analysis of laser light migration in apple tissue by Monte Carlo simulation. Progress in Agriculture Engineering Sciences 4, 45-59.

Baranyai, L., Zude, M., 2009. Analysis of laser light propagation in kiwifruit using backscattering imaging and Monte Carlo simulation. Computers and Electronics in Agriculture 69, 33-39.

Bron, I.U., Ribeiro, R.V., Azzolini, M., Jacomino, A.P., Machado, E.C., 2004. Chlorophyll fluorescence as a tool to evaluate the ripening of 'Golden' papaya fruit. Postharvest Biology and Technology 33, 163-173.

Carrara, S., Pardossi, A., Soldatini, G.F., Tognoni, F., Guidi, L., 2001. Photosynthetic activity of ripening tomato fruit. Photosynthetica 39, 75-78.

Chen, H., De Baerdemaeker, J., 1993. Finite element-based modal analysis of fruit firmness. Transactions of the ASAE 36, 1827-1833.

De Belie, N., Schotte, S., Lammertyn, J., Nicolai, B., De Baerdemaeker, J., 2000. PHpostharvest technology: Firmness changes of pear fruit before and after harvest with the acoustic impulse response technique. Journal of Agricultural Engineering Research 77, 183-191.

De Ketelaere, B., Howarth, M.S., Crezee, L., Lammertyn, J., Viaene, K., Bulens, I., De Baerdemaeker, J., 2006. Postharvest firmness changes as measured by acoustic and low-mass impact devices: a comparison of techniques. Postharvest Biology and Technology 41, 275-284.

DeEll, J.R., Prange, R.K., Murr, D.P., 1996. Chlorophyll fluorescence of Delicious apples at harvest as a potential predictor of superficial scald development during storage. Postharvest Biology and Technology 9, 1-6.

DeEll, J.R., Toivonen, P.M.A., 2000. Chlorophyll fluorescence as an indicator of broccoli quality during storage in modified atmosphere packaging. HortScience 35, 256-259.

Delwiche, M., McDonald, T., Bowers, S.V., 1987. Determination of peach firmness by analysis of impact forces. Transactions of the ASAE 30, 249-254.

Diezma-Iglesias, B., Ruiz-Altisent, M., Barreiro, P., 2004. Detection of internal quality in seedless watermelon by ícoustic impulse response. Biosystems Engineering 88, 221-230.

Diezma-Iglesias, B., Valero, C., García-Ramos, F.J., Ruiz-Altisent, M., 2006. Monitoring of firmness evolution of peaches during storage by combining acoustic and impact methods. Journal of Food Engineering 77, 926-935.

Elbatawi, I.E., 2008. An acoustic impact method to detect hollow heart of potato tubers. Biosystems Engineering 100, 206-213.

Fan, L., Song, J., Forney, C.F., Jordan, M.A., 2011. Fruit maturity affects the response of apples to heat stress. Postharvest Biology and Technology 62, 35-42.

Felföldi, J., 1996. Firmness assessment of fruits and vegetables based on acoustic parameters. Journal of Food Physics 58, 39-47.

Felföldi, J., Fekete, A., 2000. Firmness assessment by impact method, ASAE Annual International Meeting, Milwaukee. 
Funamoto, Y., Yamauchi, N., Shigenaga, T., Shigyo, M., 2002. Effects of heat treatment on chlorophyll degrading enzymes in stored broccoli (Brassica oleracea L.). Postharvest Biology and Technology 24, 163-170.

Gómez, A.H., Wang, J., Pereira, A.G., 2005. Impulse response of pear fruit and its relation to Magness-Taylor firmness during storage. Postharvest Biology and Technology 35, 209-215.

Herppich, W.B., 2001. Application potential of chlorophyll fluorescence imaging analysis in horticultural research, 6th International Symposium: Fruit, Nut and Vegetable Production Engineering, Potsdam, Germany, pp. pp 609-614.

Hitka, G., 2011. Development of the controlled atmosphere storage technology of apricot. Corvinus University of Budapest, Budapest, Hungary.

Kosson, R., 2003. Chlorophyll fluorescence and chilling injury of green pepper as affected by storage conditions. Acta Horticulturae 628, 379-385.

Krause, G.H., Weis, E., 1991. Chlorophyll fluorescence and photosynthesis: the basics. Annual Review of Plant Physiology and Plant Molecular Biology 42, 313-349.

Lu, R., 2004. Multispectral imaging for predicting firmness and soluble solids content of apple fruit. Postharvest Biology and Technology 31, 147-157.

Mattheis, J.P., Rudell, D., 2011. Responses of 'd'Anjou' pear (Pyrus communis L.) fruit to storage at low oxygen setpoints determined by monitoring fruit chlorophyll fluorescence. Postharvest Biology and Technology 60, 125-129.

Maxwell, K., Johnson, G.N., 2000. Chlorophyll fluorescence - a practical guide. Journal of Experimental Botany 51, 659-668.

Mitcham, E.J., Crisosto, C.H., Kader, A.A., 1996. Pear, Anjou, Bosc, Comice: Recommendations for maintaining postharvest quality. Department of Plant Sciences, University of California, Davis, Available at: http://postharvest.ucdavis.edu/PFfruits/PearAnjouBoscComice/, Accessed 31 October 2012.

Molina-Delgado, D., Alegre, S., Barreiro, P., Valero, C., Ruiz-Altisent, M., Recasens, I., 2009. Addressing potential sources of variation in several non-destructive techniques for measuring firmness in apples. Biosystems Engineering 104, 33-46.

Nedbal, L., Soukupova, J., Whitmarsh, J., Trtilek, M., 2000. Postharvest imaging of chlorophyll fluorescence from lemons can be used to predict fruit quality. Photosynthetica 38, 571-579.

Peng, Y., Lu, R., 2006. Improving apple fruit firmness predictions by effective correction of multispectral scattering images. Postharvest Biology and Technology 41, 266274.

Peng, Y., Lu, R., 2007. Prediction of apple fruit firmness and soluble solids content using characteristics of multispectral scattering images. Journal of Food Engineering 82, 142-152.

Prange, R.K., DeLong, J.M., Leyte, J.C., Harrison, P.A., 2002. Oxygen concentration affects chlorophyll fluorescence in chlorophyll-containing fruit. Postharvest Biology and Technology 24, 201-205.

Purvis, A.C., 2002. Diphenylamine reduces chilling injury of green bell pepper fruit. Postharvest Biology and Technology 25, 41-48.

Qin, J., Lu, R., 2007. Measurement of the absorption and scattering properties of turbid liquid foods using hyperspectral imaging. Appl. Spectrosc. 61, 388-396. 
Qin, J., Lu, R., 2008. Measurement of the optical properties of fruits and vegetables using spatially resolved hyperspectral diffuse reflectance imaging technique. Postharvest Biology and Technology 49, 355-365.

Qin, J., Lu, R., 2009. Monte Carlo simulation for quantification of light transport features in apples. Computers and Electronics in Agriculture 68, 44-51.

Ragni, L., Berardinelli, A., Guarnieri, A., 2010. Impact device for measuring the flesh firmness of kiwifruits. Journal of Food Engineering 96, 591-597.

Romano, G., Argyropoulos, D., Nagle, M., Khan, M.T., Müller, J., 2012a. Combination of digital images and laser light to predict moisture content and color of bell pepper simultaneously during drying. Journal of Food Engineering 109, 438-448.

Romano, G., Baranyai, L., Gottschalk, K., Zude, M., 2008. An approach for monitoring the moisture content changes of drying banana slices with laser light backscattering imaging. Food and Bioprocess Technology 14, 410-414.

Romano, G., Nagle, M., Argyropoulos, D., Müller, J., 2011. Laser light backscattering to monitor moisture content, soluble solid content and hardness of apple tissue during drying. Journal of Food Engineering 104, 657-662.

Romano, G., Nagle, M., Müller, J., 2012b. Monitoring physical parameters of tropical fruits suring drying by application of laser light in the VIS/NIR spectrum, CIGRAgEng Valencia, Spain.

Saquet, A.A., Streif, J., 2002. Chlorophyll fluorescence as a predictive method for detection of browning disorders in Conference pears during controlled atmosphere storage. Acta Horticulturae 596, 863-866.

Schotte, S., De Belie, N., De Baerdemaeker, J., 1999. Acoustic impulse-response technique for evaluation and modelling of firmness of tomato fruit. Postharvest Biology and Technology 17, 105-115.

Taniwaki, M., Hanada, T., Sakurai, N., 2009a. Postharvest quality evaluation of "Fuyu" and "Taishuu" persimmons using a nondestructive vibrational method and an acoustic vibration technique. Postharvest Biology and Technology 51, 80-85.

Taniwaki, M., Hanada, T., Tohro, M., Sakurai, N., 2009b. Non-destructive determination of the optimum eating ripeness of pears and their texture measurements using acoustical vibration techniques. Postharvest Biology and Technology 51, 305-310.

Taniwaki, M., Takahashi, M., Sakurai, N., 2009c. Determination of optimum ripeness for edibility of postharvest melons using nondestructive vibration. Food Research International 42, 137-141.

Tijskens, L.M.M., van Kooten, O., Otma, E.C., 1994. Photosystem 2 quantum yield as a measure of radical scavengers in chilling injury in cucumber fruits and bell peppers. Planta 194, 478-486.

Valente, M., Leardi, R., Self, G., Luciano, G., Pain, J.P., 2009. Multivariate calibration of mango firmness using vis/NIR spectroscopy and acoustic impulse method. Journal of Food Engineering 94, 7-13.

van Kooten, O., Snel, J., 1990. The use of chlorophyll fluorescence nomenclature in plant stress physiology. Photosynth Res. 25, 147-150.

von Willert, D.J., Matyssek, R., Herppich, W., 1995. Experimentelle Pflanzenökologie. Grundlagen und Anwendungen Thieme, Stuttgart, Germany.

Wanitchang, P., Terdwongworakul, A., Wanitchang, J., Nakawajana, N., 2011. Nondestructive maturity classification of mango based on physical, mechanical and optical properties. Journal of Food Engineering 105, 477-484. 
Woolf, A.B., Laing, W.A., 1996. Avocado fruit skin fluorescence following hot water treatments and pretreatments. J. Amer. Soc. Hort. Sci. 121, 147-151.

Wright, H., DeLong, J., Harrison, P.A., Gunawardena, A.H.L.A.N., Prange, R., 2010. The effect of temperature and other factors on chlorophyll a fluorescence and the lower oxygen limit in apples (Malus domestica). Postharvest Biology and Technology 55, 21-28.

Yang, X., Song, J., Fillmore, S., Pang, X., Zhang, Z., 2011. Effect of high temperature on color, chlorophyll fluorescence and volatile biosynthesis in green-ripe banana fruit. Postharvest Biology and Technology 62, 246-257.

Zsom-Muha, V., Felfödi, J., 2007. Vibration behavior of long shape vegetables. Progress in Agricultural Engineering Sciences 3, 21-46.

Zsom, T., Zsom-Muha, V., Baranyai, L., Herppich, W.B., Felföldi, J., Balla, C., 2010. Nondestructive determination of post-harvest ripening of capsicum $\times$ annum 'Kárpia'. Acta Horticulturae 858, 407-412. 